\title{
Translation, Rewriting and Creation: Interview of Professor Noël Dutrait, Translator of Gao Xingjian's Lingshan (La Montagne de l'âme) ${ }^{1}$
}

\author{
Mingxing Wang \\ University of Alberta
}

Noël Dutrait is Professor of Chinese language and literature at the Department of Asian Studies of the University of Aix-Marseilles, France. He is also a leading translator, who during the past thirty years or so, has tirelessly translated into French the works of such well-known contemporary Chinese writers as Wang Meng, A Cheng, Han Shaogong, Su Tong, Gao Xingjian and Mo Yan. In particular, his French version of Gao Xingjian's novel, Lingshan (La Montagne de l'âme in French; Soul Mountain in English) has been widely accepted as an excellent rendition. Professor Dutrait's translation is believed to help Western readers understand and appreciate the Chinese world Gao constructed and imagined from his own travel experience, henceforth contributing to Gao's winning the Nobel Prize in 2000. In addition, Dutrait's translation of the 2012 Chinese Nobel laureate, Mo Yan's Jiu Guo (Le Pays de l'alcool) won Le Prix Larue Batallion for the best translation in 2004. The following text is an edited version based on the interview in French conducted at Prof. Dutrait's office on September 28, 2015.

\section{Translating Lingshan (La Montagne de l'âme)}

Wang: Professor Dutrait, thank you for accepting my interview. I enjoyed reading your critical reviews about Lingshan a lot. Would you like to talk a little about how you translated Gao's most important novel into French?

Dutrait: When I translated the novel, I actually only leafed through the original novel. I read the first few chapters, not the whole book though. I had known Gao himself for quite a while before I commenced the project. I always wanted to translate the works he had accomplished. His works were so interesting, so refreshing to me. As early as the 1980s, Gao published his Che Zhan (Bus Stop) and other plays, establishing himself as a leading modernist dramatist in China. At a dinner when he was already in France in the early 1990s, he asked me: "Look, at the moment, I don't have a translator to render my novel (Lingshan) into French. I'm wondering if you would like to do the project."

Wang: In the early 1980s, you discussed with Gao about the emerging modernist literary trend in China when you were doing research in Beijing.

Dutrait: That's right.

${ }^{1}$ A brief French version of this interview was published in Alternative Francophone, Vol 2, No. 2, 2017. 
Wang: So, when you translated Lingshan, did you like the modernism inspired techniques in this novel?

Dutrait: Yes. When I read some chapters of Lingshan, I found it very original. Some literary traits were so different from other works at the time.

Wang: Did you find some influences from Duras in this novel, for example?

Dutrait: Yes. Apparently, in Gao's novel, he adopts a Durassian poetic use of pronouns. So, "il dit", "elle dit", "tu dis" / "vous dites," "je dis" become wo shuo (I say), li shuo (you say), and ta shuo (s/he says). Setting this aside, in general I found his Lingshan a very original novel. In particular, its literary approaches distinguish it from other Chinese novels. That's the reason why I wanted to translate this novel.

Wang: When you translated Gao's novel, you had already rendered the works of such well-known authors as A Cheng and Han Shaogong. What translational approaches did you adopt respectively?

Dutrait: There are two differences when I translated A Cheng and Han Shaogong's works. First of all, I didn't know any of them. I only met them after my translations had been published. At that time, it was natural. Another difference is that I translated better when I had some help from some Chinese students who were studying at the University (L'Université de Provence). They helped me understand the Chinese texts and contexts better. Without their help, I could not render well the texts that are filled with the authors' life experiences. As for translating Gao Xingiian's novel, it was different. When I finished the first fifty pages, I sent them to him to take a look, and then we worked on the drafted version together. He would offer his opinions and suggestions about the French version, as his French was very good. He would tell me that such and such words were a better choice and certain rhythm of the text should be changed. In addition, he said that the Chinese proverbs could be changed to the corresponding French proverbs - it could be considered as a rewriting. So, you can see the differences between my approach between Han Shaogong and A Cheng, and Gao Xingjian. For the former, I worked alone. As with the case of Gao Xingjian, I worked closely with the author himself.

Wang: Concerning the level of language, there is also a difference between them. For A Cheng and Han Shaogong, their use of the literary language is based on the common core of the Chinese language, whereas both Chinese and French shaped Gao's literary sensibility-he was much influenced by French literature. Is that not so?

Dutrait: I also find Gao's case applies to Han and A Cheng. Despite the influences, Gao himself first reads French literature and then writes in his own way. Gao reads Western literature. Han also reads Márquez and Western literature.

Wang: But there is a difference. Han and A Cheng read Western literature in translation, whereas Gao reads original French literature.

Dutrait: Of course, Gao writes differently than other Chinese writers. 
Wang: During your tour in Taiwan in 2014, you said that for the first hundred pages of your translation, you had a lot of references, for example, the novels by Marguerite Duras and Georges Perec. Are there any other particular French writers?

Dutrait: It was Gao himself who told me to read Georges Perec's novel Un homme qui dort (A Sleeping Man). He wanted his French version to be like Perec's style in general. Other writers I can think of are Marguerite Duras, and perhaps Michel Butor who wrote La Modification. The latter also uses "vous" as narrator in his novel. Gao did the same in his own novel.

Wang: In fact, in Gao's short stories in the early 1980s, he already used the same narrative technique. Concerning translation, before you began to translate Lingshan, had you and Gao discussed the principles that should guide your translation?

Dutrait: In general, no. For me, I'm more of a pragmatist than a theorist. I read literature and translate what is going through my head. Of course, I could show what I translated to Gao, and he could suggest to me to make certain improvements here and there. But most often, I had to translate alone, as I didn't want to bother him much. After I finished my translation, he would read my draft and then tell me "very good" or "ok", or ask me to add an annotation. Despite this, I would not say that there was a big principle of translation, but for Gao Xingjian, there is a major principle — "don't hesitate to rewrite. You may distance yourself from the source language. If there is a sentence you need to change completely, change it". This is important for me.

Wang: Even rewrite?

Dutrait: Yes, rewrite. Sometimes creation is necessary. But I told Gao: "I'm not a writer myself". As I didn't write a novel myself, what I could do was to write better to achieve the best result in my capacity. For Gao, editing is not an act of betrayal, which means that you don't have to compromise what a writer wants to say. Especially, Gao can always verify if he is "betrayed", as we call it in French. But as a principle, editing shouldn't come before translating. Though there are certain things that are quite complicated, in my opinion, editing should always come after. An author has a more important role to play when a translator is at his or her side. That's the ethics I respect. That's it.

Wang: According to the relevant published materials, the English translator of Gao's Lingshan, Mabel Lee, said that Gao's style is of minimalism, whereas Gao's Swedish translator, Göran Malmqvist, said that Gao's language is pure. What do you think?

Dutrait: Perhaps minimalism doesn't describe Gao's work very well. What Gao uses in his novel is "verbal stream". Thus it is a little bit like "Stream of Consciousness". The writer narrates what comes into his mind. For Gao, that's the language to write the things that are inspired by the living reality around. For example, when you travel in the woods, what the author tries to relate are the things in his mind-capturing them in words in a free manner. I don't think it's minimalism. On the other hand, there are a lot of different chapters in the novel. In the chapters where the author is in the woods, in 
a temple, or in the middle of listening to music, etc., the language used is a verbal stream. Words, words, coming in one after another. When he writes, for example, about the life in Beijing, his debates with his friends, especially his relations with women are more minimalist- these are the trivialities of daily life. Little by little, those details accumulate as a verbal stream.

Wang: That's more like short expressions, simple style?

Dutrait: Yes, at the beginning, very simple, but gradually more complicated words and expressions follow.

Wang: Concerning the comments about Gao's use of pure language in his novel, what would you like to say?

Dutrait: I don't know what "pure" means?

Wang: Maybe it refers to the purity of the Chinese language.

Dutrait: But sometimes I didn't understand certain expressions in the novel and asked Gao about them. He would simply tell me that they were all language games. This amused me a lot. But that's not simple.

Wang: Maybe it also refers to a core Chinese without the influences from the West.

Dutrait: Yes, but he also got some influences from Western literature. As you see, he studied French literature, but was not necessarily influenced by it. In my opinion that's a good thing, as it sets a tone for his novel. But according to Professor Malmgvist, his use of language has nothing to do with political and ideological jargons at the time, maybe it's true in that sense.

Wang: Like Gao said, he didn't like politics and propaganda in literature.

Dutrait: He didn't like the Chinese named by Mao Tse Tung. He said that he did a lot of harm to China. But at the same time he has been inspired by many Chinese writers, especially the classical ones. The reason perhaps for being awarded the Nobel Prize lies in his sufficient knowledge about Western literature, French literature in particular, and Chinese classical literature. Through his novels, a common space has been created to allow the Western audience to understand Chinese culture, like the great Chinese writer, Lu Xun (1881-1936).

Wang: But there is a difference. While Lu Xun's works embrace foreign elements, Gao appreciates classical Chinese language a lot.

Dutrait: Yes, you are right, but he couldn't return to that epoch. When he wrote Lingshan, Gao used a lot of contemporary Chinese expressions. He read a lot of classical literary works too. In order to write, he could not reject traditional Chinese.

Wang: His language style is quite colloquial. 
Dutrait: That's right.

Wang: His style is not at all the classical style.

Dutrait: Absolutely.

Wang: So, there is a difference between what he thinks and what he really does.

Dutrait: That's true. The colloquial style of Lingshan, both Chinese and French, is well represented, especially registering the comic tone nicely; the verbal stream in the novel is beautiful.

Wang: Let's return to the process of your translation. As indicated, you did translation alone after you had translated the first one hundred pages or so with the cooperation of Gao?

Dutrait: Not always like this. After I finished the first one hundred pages, I did the translation alone, but when Gao came to Aix from time to time, I would always let him take a look at my drafts. Since it took three years for me to translate the novel, I also sent him my drafts.

Wang: What did you both discuss the most?

Dutrait: After so many years, I can't remember very clearly.

Wang: Style, or something?

Dutrait: For me, comprehending the text was an issue, which means when one says this or that, I don't know what s/he refers to. Now I could still remember that when I couldn't understand certain texts, I would fax my questions to Gao-I used my fax machine a lot at the time. When he received my faxes, he could immediately give me some suggestions.

Wang: Given some differences between Chinese and French, did he also suggest that such and such translations were not so French?

Dutrait: No, he had full confidence in my French.

Wang: In your recent article about translating Lingshan, you said that when Gao found certain expressions in your drafts not so French, you would give him another option.

Dutrait: That happened.

Wang: So. He preferred a naturalized version, maybe?

Dutrait: That's true. There is an example that I could still remember clearly. This has something to do with the use of the French "on" instead of "nous". In French we say "nous sommes allés à Marseilles", but in oral French, we normally use "on est allé à Marseilles". Though the latter could be used in written format, it is not good French. In written language, we shouldn't mix "nous" and "on". 
For Gao, he wanted to use "on" instead of "nous". I discussed it a lot with him. I couldn't use "on" in a novel as a narrative form. So I had to find something else-neither "nous", nor "on".

Wang: On many occasions, you said that we need creation in translation. At what levels do you think creation is necessary, taking Lingshan as an example.

Dutrait: Of course, in Lingshan, I could do this because the author was okay with it. How should I put it? I would say that we needed to create and recreate something. I couldn't be content with creating a sense for sense, or word-for-word paraphrase. Sometimes, we had to think of the sentences, and when I found some good usages that could really match them, I didn't hesitate to do it. It is still a creation. Of course, it needed a certain creative force. Thanks to my extensive reading, I could do itI read world literature a lot. Modern translations of world literature helped me a lot. So, I could create and recreate like an author.

Wang: In your translation process, what difficulties did you encounter most often?

Dutrait: Generally, in terms of translation, Lingshan in particular, it is always tense and corresponding verbs that challenge me the most. Should I use the present, simple past, past continuous, past perfect or past perfect continuous? These are the most complicated things, as the Chinese language structure doesn't clearly indicate time sequence. At the beginning of my translation of Lingshan, I put all the sentences in the present tense. The first sentence in La Montagne d'âme (Soul Mountain) is like that of Marguerite Duras. However, as the novel is quite long, it is impossible to use the same tense throughout. That's the cause of the difficulties.

Wang: The sentence structure of Gao is quite idiosyncratic.

Dutrait: Yes.

Wang: Sometimes I have the impression that his sentence structure is not typical of ordinary Chinese narrative. For example, in the first few sentences of Chapter 1, those sentences are loosely connected-there are no clear relational markers.

Dutrait: Indeed, in Chinese, there are no clear tense sequences-past, present or future. So that's the most difficult thing in translation.

Wang: I can see that your indicator of tense is quite precise in your French translation.

Dutrait: In French, we need to be precise. If the beginning of the novel uses present tense, we have to do the rest in the present tense; the same is true of the past tense. During my translation, it is difficult to know when to use a tense, but I have to be exact. So, you need to contextualize the sentences.

Wang: Do you have other difficulties? 
Dutrait: Another difficulty involves the rendering of the old Chinese set phrases or expressions, old songs, poems. Some of them are more or less invented by Gao. Yes, it is difficult to translate them. Sometimes I showed Gao my translation. He would say that I could rewrite it. I could not remember exactly the details of how I rendered them, but I roughly remember that there is a beginning passage with a French rhyme I invented. The chapter is ended with rhyme: "Partira, partira, partira pas, mais là ne reste pas, le vent du fleuve est froid". I invented the rhyme; I changed the sentences so completely that they had nothing to do with the Chinese rhyme scheme. Gao was happy with it and said that it was wonderful.

Wang: Anyhow it means something in French. You said that your version is not a literal translation of the source text, but you also said that you refused to rewrite. It is a little contradictory, isn't it?

Dutrait: Yes. What I should say is that we can't respect the source text when the situation is too complicated, or we can create for the time being if the author agrees. It is funny that when one door is opened, another is still there. But when the source text is not easy for the French readers to understand, we have to rewrite a little.

Wang: But there is limit to it, isn't there?

Dutrait: Yes, there should be a limit. If we rewrite too much, then it is no longer the work of Gao Xingjian, in any case.

Wang: I remember that some translation critics said that if Mo Yan's translator found the sentences in the author's works were not good enough, he wouldn't hesitate to delete them, or rewrite them.

Dutrait: But he said that Mo Yan allowed him to do that.

Wang: Anyhow, we should respect the author.

Dutrait: For me, I did my best to show my maximum respect to the author, though I might make some wrong choices in my translation. I don't have any intention to be a writer.

Wang: You don't want to be an editor! But in the English version of Lingshan, Mabel Lee did a similar thing as Mo Yan's translator did.

Dutrait: That's true. But Gao also authorized her to do what she felt like doing. The English version was criticized by some people. However, I haven't read the English version, and so I can't verify the truth of some criticisms. I choose to believe in her translation.

Wang: Was Mr. Gao aware of the criticisms?

Dutrait: Yes. He was aware of that. He told me that quite often some people were jealous, as they tried to ask Gao to let them translate Lingshan, but he wouldn't. He would rather let Mabel Lee do it.

Wang: That's not so simple, is it? 
Dutrait: For Gao, she is a very good translator, a respectful friend. Despite the criticism, the English version has been selling well. The English version sells even better than the French version. Everywhere in the world, the readers have access to Gao's novels through Lee's English translation.

\section{Translating Chinese literature in the French context}

Wang: In the history of French translation, there are a lot of approaches to translating Chinese texts. For example, in the $19^{\text {th }}$ century, Judith Gauthier played a key role in introducing Chinese poetry into French. She perhaps altered the Chinese poetic style, adapting it to French Romanticism of the time.

Dutrait: That's right.

Wang: But in the contemporary context, the way of translating has changed a little. For example, François Cheng has translated Lao She's Rickshaw Camel and written a French novel Le Dit de Tianyi. It seems to me that Mr. Cheng translated a lot of Chinese phrases and idioms into his French novel, or other texts, sometimes with careful explanations. How do you situate your work in such a context?

Dutrait: I favour a translational approach with little theoretical consideration. Just as I said many times, I don't favour theory in my translation. I'm more of a pragmatist... I deal with one problem after another each time. I try to control these problems according to the writer's will as much as possible. Based on that, I may try to make creations in the target text. There is a possibility of creation, but a very limited one. We always have to respect the author, always! I can't define my practice any other way than pragmatic.

Wang: In the French context, Antoine Berman, Henri Meschonnic, Pascale Casanova figure prominently. Pascale is different. For her, one has to translate to approach a dominant centre. In a certain sense, it means that one has to cater to readers.

Dutrait: For me, I do translation differently. That is, I respect the author. I put what an author tries to say in good French. That's what I want to do in my utmost effort, though sometimes it is difficult. If you really translate word by word, the end result of your version will be unreadable. That is what it shouldn't be. I don't know much these theoretical monographs, such as those by Berman, though I leafed through them. I'm afraid that these theories might imprison me.

Wang: Berman's approach is one of the contemporary ones. He was also somewhat pragmatic.

Dutrait: That's true.

\section{Translation and the Nobel Prize}


Wang: Many critics suggested that thanks to Malmqvist's recommendation of Gao and your French translation of his Lingshan, Gao won the Nobel Prize. You mentioned that the Nobel Prize Committee evaluated Gao's Lingshan based on your French version, is that true?

Dutrait: Yes, the secretary of the Swedish Academy-I forgot his name, told me that they evaluated Gao's Lingshan according to my French version. ${ }^{2}$

Wang: As I know, a lot of members of the Academy can read French.

Dutrait: Many of them are francophone. In addition, at the time, the English version was not yet published. Gao sent them some parts of the translated English version, but only the French version played an important role in the evaluation process of the committee.

Wang: Was it the same reason that Mo Yan asked you to translate his Fengtun feinu (Beaux seins, belles fesses in French/Big Breasts, Wide Hips in English) in 2004?

Dutrait: Actually, Mo Yan didn't ask me to translate it. It was his editor that asked me to translate his novel.

Wang: Which publishing house?

Dutrait: Le Seuil. The first of Mo Yan's novels that I translated was his Jiu Guo (The Republic of Alcobol). The publisher wrote to me, asking if I would like to translate the book. At the time, I didn't know Mo Yan. After its publication, I got to know Mo Yan himself and asked a lot of questions about the novel. As the French translation of Jin Guo, Le Pays d'alcool was sold extremely well, the publisher asked me again to translate his Fengtun feinu (Beaux seins, belles fesses). It was not Mo Yan's choice, but that of the publisher. Some other French translators have also translated Mo Yan's major novels, the most wellknown translator is Chantal Chen-Andro. Actually, it is the publishing house that decides who could translate such and such an author.

Wang: Le Seuil chose you to translate Mo Yan's novels, perhaps based on your reputation?

Dutrait: Not particularly at the time, simply because there was a very limited number of professionals who translated Chinese literature. There were no more than ten translators who did the job in France. Le Seuil was so kind to have us, including Chantal Chan and me, work on these projects. Of course, after the Nobel Prize, both Chantal and I also had a certain reputation.

Wang: Yes, the French daily newspaper, La Provence, said that "our translator had discovered Gao Xingjian” before his wining of the Nobel Prize. It was important, wasn't it?

2 Probably Professor Dutrait was talking about the permanent secretary, Horace Engdahl, of the Swedish Academy in Stockholm, who announced Gao as the winner of the Nobel Prize in 2000. 
Dutrait: Yes, of course.

\section{Retranslation}

Wang: As you said in the recent edition of the online journal, Le Chantier, you will retranslate Lingshan.

Dutrait: Did I say it?

Wang: You seemed to say that in the near future, you will retranslate Lingshan.

Dutrait: But for the moment, my translation is okay. Maybe as a future project. On many occasions, I said that somebody else could try to translate Lingshan one day.

Wang: It is understandable that we need different versions of the same work, isn't it?

Dutrait: Actually, in the most recent Seuil edition of the Nobel Writers' series, I made some corrections to my translation.

Wang: What did you correct?

Dutrait: I could not remember much of the details, but all are small things, such as punctuation and sentence corrections. Not so much though.

Wang: Were there anything that you were not satisfied with?

Dutrait: In fact, it was the editor who suggested to me that such and such a word needed to change. But in general, very little was changed.

Wang: In the first L'Aube edition of La Montagne de l'âme, the editor also suggested to you to revise something?

Dutrait: Yes. But not too much.

Wang: Based on your translating Lingshan, do you think that you were connected to the contemporary currents of translation thoughts? How do you contribute to the theory of translation?

Dutrait: As I said a few minutes ago, I'm not so keen on translation theory.

Wang: Perhaps it is the translation scholars' job to examine and theorize your translations.

Dutrait: That's right.

\section{Postscript:}


Before my interview was over, Professor Noel Dutrait added that the contribution of his co-translator and deceased wife, Liliane Dutrait could not be forgotten. Thanks to Liliane's high sensitivity to the sound of the language and literary style, the translation of Lingshan has become such a successful work. Professor Dutrait emphasized modestly that Liliane's linguistic ability perhaps exceeded his. 